\title{
Effects of the Form Factor and the Force of the Gravity on the Thermal Exchanges by Natural Convection in a Rectangular Cavity Filled with Nanofluid
}

\author{
L. Eljamali, A. Wakif, Z. Boulahia, M. Zaydan, R. Sehaqui \\ Faculty of Science Ain Chock, Mechanical Laboratory, Hassan II University, Casablanca, Morocco \\ Email: Laila.eljamali@gmail.com
}

How to cite this paper: Eljamali, L., Wakif, A., Boulahia, Z., Zaydan, M. and Sehaqui, R. (2019) Effects of the Form Factor and the Force of the Gravity on the Thermal Exchanges by Natural Convection in a Rectangular Cavity Filled with Nanofluid. Engineering, 11, 59-73.

https://doi.org/10.4236/eng.2019.111006

Received: November 23, 2018

Accepted: January 28, 2019

Published: January 31, 2019

Copyright $\odot 2019$ by author (s) and Scientific Research Publishing Inc. This work is licensed under the Creative Commons Attribution International License (CC BY 4.0).

http://creativecommons.org/licenses/by/4.0/

(c) (i) Open Access

\begin{abstract}
Effects of the form factor on natural convection heat transfer and fluid flow in a two-dimensional cavity filled with $\mathrm{Al}_{2} \mathrm{O}_{3}$-nanofluid has been analyzed numerically. A model was developed to explain the behavior of nanofluids taking account of the volume fraction $\varphi$. The Navier-Stokes equations are solved numerically by alternating an implicit method (Method ADI) for various Rayleigh numbers varies as $10^{3}, 10^{4}$ and $10^{5}$. The nanofluid used is aluminum oxide with water $\operatorname{Pr}=6.2$; solid volume fraction $\varphi$ is varied as $0 \%, 5 \%$ and $10 \%$. Inclination angle $\Phi$ varies from $0^{\circ}$ to $90^{\circ}$ with a step the $15^{\circ}$ and the form report varies as $R=0.25,0.5,1$ and 4 . The problem considered is a two-dimensional heat transfer enclosure. The vertical walls are differentially heated; the right is cold when the left is hot. The horizontal walls are assumed to be insulated. The nanofluid in the cavity is considered as incompressible, Newtonian and laminar flow. The nanoparticles are assumed to have a shape and a uniform size. However, it is supposed that the two fluid phases and nanoparticles are in a state of thermal equilibrium and they sink at the same speed. The thermophysical properties of nanofluids are assumed to be constant at the exception of the variation of density in the force of buoyancy, which is based on the approximation of Boussinesq values.
\end{abstract}

\section{Keywords}

Nanofluid, Heat Transfer, Thermal Exchanges, Natural Convection, The Force of the Gravity, Form Factor

\section{Introduction}

The improvement of the heat transfer by natural convection is the main object of 
several studies; many researchers have conducted a series of tests numerical and experimental of the description of the phenomena of convection: the manager of fact, the nature of the systems (in particular the geometry) and the properties of fluids involved (physico-chemical properties).

Bairi et al. [1] have conducted a study on the natural convection for a Rayleigh number high to the assistance of a technical numerical and experimental in a rectangular cavity tilted. They have obtained a correlation giving the Nusselt number in function of Rayleigh of this study; the Nusselt number minimum is obtained for $\Phi=270^{\circ}$. Hakan F. Ozrop Eiyad Abu-Nada [2] conducted numerical studies to analyze the effect of the use of different nanofluids on the distribution of fields of high temperatures in a cavity of height $\mathrm{H}$ and length $\mathrm{W}$ filled with a mixture of water and of nanoparticles $\left(\mathrm{Cu}, \mathrm{Al}_{2} \mathrm{O}_{3}\right.$ and $\left.\mathrm{TiO}_{2}\right)$. The left wall is maintained at a constant temperature higher than the temperature of the right wall. They have shown that the value of the Rayleigh number, the size of the heating device and the volume fraction of the nanofluids effect on the strength of heat transfer. Kamal Raj Kumar Tiwari and ManabDas [3] have conducted numerical studies to analyze the effect of nanofluids on the distribution of the temperature field, the flow lines in a cavity filled with a mixture of water and type of nanoparticles of copper and for different volumetric fractions. They showed that the coefficient of heat exchange is influenced by the Reynolds number and the volume fraction of nanofluid. Nanotechnology has been widely used in industry as materials with nanometer sizes possess unique chemical and physical properties. The nanoscale fluids added are called nanofluids which are used for the first time by Choi [4]. Khanafer et al. [5] have studied the improvement of heat transfer in an enclosure to two dimensions by using the nanofluids for various relevant parameters. They have tested different models from the density of the nanofluid, viscosity and thermal expansion coefficients. They found that nanoparticles in suspension significantly increase the rate of transfer of heat to all number of Grashof.

G. de Vahl Davis et al. [6] have used the method of finite differences to resolve the problem of natural convection in a square cavity differentially heated. These studies have had the merit to launch an international competition on the subject. They have shown that the temperature distribution at mid-height of the cavity is almost linear and the gradient vertical heat tends toward zero for the values of the Rayleigh number inferior than $10^{4}$. G. de Vahl Davis [7] has proposed a standard solution known as the benchmark for the case of the square cavity differentially heated in laminar regime. The formulation of the problem done by Davis is the formulation stream function-vorticity. The modified equations by the interaction of a transitional term are discretized by the method of finite differences. The system of an algebraic equation resulting from the operation of discretization is solved by the algorithm ADI (Alternating direction implicit). Zaydan et al. [8] they studied numerically the laminar natural convection of a nanofluid confined in a square cavity. The vertical walls are supposed to be isolated, non-conductor and impervious to the transfer of mass. The horizontal 
walls are differentially heated, the low wall is maintained to a warm temperature (sine) and the high wall is cold. His study is to develop a new method of accurate resolution of height to solve the equations of heat transfer. The new method is a compact of the fourth order (F.O.C). His work aims to show the interest of the method and to understand the effect of the presence of nanofluids in closed systems squares on the mechanism of the natural convection. The numerical simulations are carried out for a Prandtl number $(\operatorname{Pr}=6.2)$, for the different volume fractions $\varphi$ Varies between $0 \%$ and $10 \%$ for the nanofluid (water $+\mathrm{Cu}$ ) and the Rayleigh numbers between $R a=10^{3}$ and $R a=10^{5}$. Markatos and Pericleous [9] have studied numerically, the phenomenon of natural convection in a square cavity filled with air and differentially heated for values of the Rayleigh number included in the interval $10^{3} \leq R a \leq 10^{6}$. Jou and Tzeng [10] use of nanofluids to improve the heat transfer by natural convection in a rectangular enclosure. They conducted a numerical study using the model Khanafer. They indicated that the volume fraction of nanofluid causes an increase in the coefficient of thermal transfer medium. Barakos et al. [11] have analyzed numerically the natural convection in a square cavity using an approach of volume of the control. Their calculations were made for laminar flows and turbulent with and without functions of logarithmic walls for a series of functions for Rayleigh up to $10^{10}$. The solution captures very well all flow and heat transfer phenomena, especially near the walls where dense, non-uniform grids are used in the thin boundary layers constituted there. Elsherbiny [12] an experimental study conducted from June to pay Studying heat transfer by natural convection in an inclined rectangular cavity. In this work we are interested in the study of the code thermal transfer digital in inclined cavity in relation to the horizontal, in order to study the influence of the inclination angle, the form factor and the volume fraction on the transfer of heat. The main objective of this study is to examine the heat transfer by natural convection in inclined enclosure fully heated filled with nanofluids. In this context, we have established our own code in solving the problem discretized by the method ADI (alternating direction implicit).

\section{Mathematical Description of the Problem}

The configuration has studied is show in Figure 1. It is a square cavity tilted in relation to the horizontal axis filled with a mixture of water and of nanoparticles of $\mathrm{Al}_{2} \mathrm{O}_{3}$, including two walls are maintained at the respective temperatures $T_{H}$ hot and cold $T_{C}$ the other walls are supposed, adiabatic. The form factor of the cavity is defined as $R=H / W$.

The nanofluid in the cavity is considered incompressible and Newtonian, the flow is assumed to be laminar and two-dimensional; the liquid phase and nanoparticles are in a state of thermal equilibrium. According to the approximations Boussinesq, the variation of density is negligible everywhere except in the term of buoyancy.

The thermophysical properties with which we will work are described in Table 1 . 


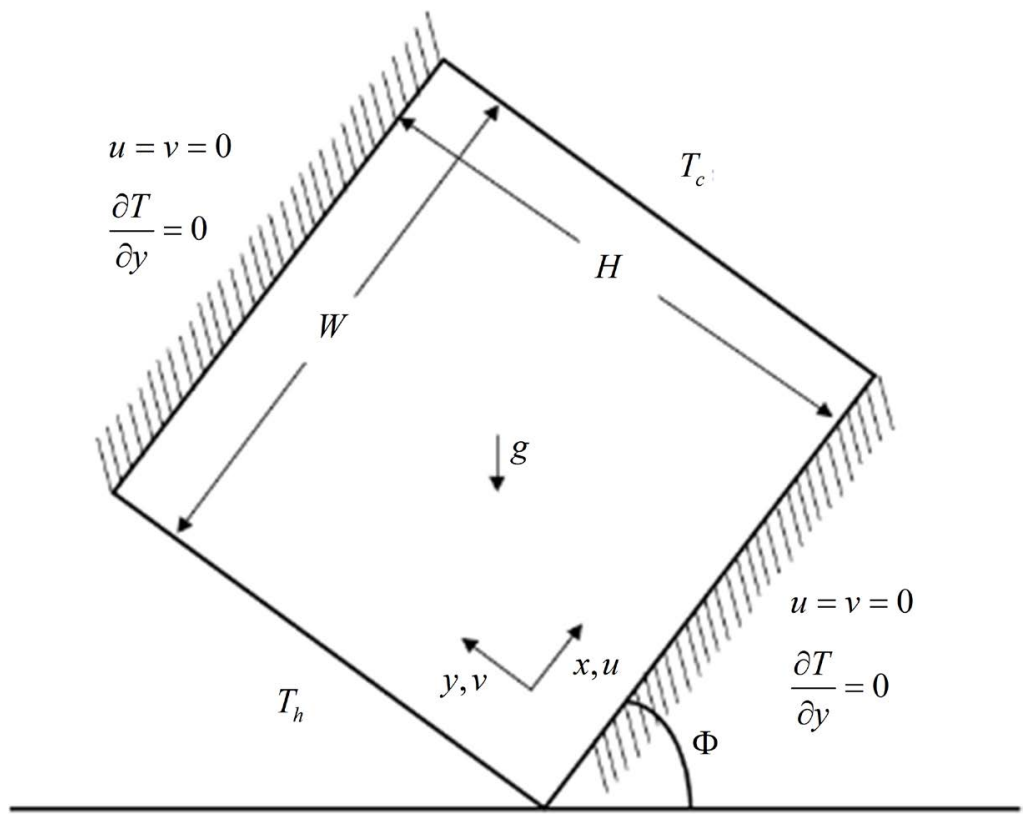

Figure 1. Physical model and coordinate system.

Table 1. Thermophysical properties of different phases.

\begin{tabular}{ccc}
\hline property & Fluid phase (water) & Solid phase (copper) \\
\hline$C_{p}(\mathrm{~J} / \mathrm{kg} \cdot \mathrm{K})$ & 4179 & 765 \\
$\rho\left(\mathrm{kg} / \mathrm{m}^{3}\right)$ & 997.1 & 3970 \\
$K(\mathrm{~W} / \mathrm{m} \cdot \mathrm{K})$ & 0.613 & 40 \\
$\alpha\left(\mathrm{m}^{2} / \mathrm{s}\right)$ & $1.47 \times 10^{-7}$ & $131.7 \times 10^{-7}$ \\
$\beta(1 / \mathrm{K})$ & $21 \times 10^{-3}$ & $0.85 \times 10^{-3}$ \\
\hline
\end{tabular}

Under the assumption of thermal properties constants, the Navier-Stokes equations for an incompressible fluid, unsteady, two-dimensional and are:

- Continuity equation:

$$
\frac{\partial u}{\partial x}+\frac{\partial v}{\partial y}=0
$$

- $x$-momentum equation:

$$
\rho_{n f}\left(u \frac{\partial u}{\partial x}+v \frac{\partial u}{\partial y}\right)=-\frac{\partial P}{\partial x}+\mu_{n f} \Delta_{2} u\left(\rho_{s} \beta_{s} \varphi+(1-\varphi) \beta_{f} \rho_{f}\right) \cdot T \cdot g \cdot \sin (\phi)
$$

- $\quad y$-momentum equation:

$$
\rho_{n f}\left(u \frac{\partial v}{\partial x}+v \frac{\partial v}{\partial y}\right)=-\frac{\partial P}{\partial y}+\mu_{n f} \Delta_{2} v\left(\rho_{s} \beta_{s} \varphi+(1-\varphi) \beta_{f} \rho_{f}\right) \cdot T \cdot g \cdot \cos (\phi)
$$

- Energy equation:

$$
u \frac{\partial T}{\partial x}+v \frac{\partial T}{\partial y}=\alpha_{n f}\left[\frac{\partial^{2} T}{\partial x^{2}}+\frac{\partial^{2} T}{\partial y^{2}}\right]
$$

- Kinematics equation: 


$$
\frac{\partial^{2} \psi}{\partial x^{2}}+\frac{\partial^{2} \psi}{\partial y^{2}}=-\omega
$$

where $\quad \alpha_{n f}=\frac{k_{n f}}{\left(\rho \cdot c_{p}\right)_{n f}}$

- The effective viscosity of the fluid containing a dilute suspension of small particles rigid spherical is given by Brinkman:

$$
\mu_{n f}=\frac{\mu_{f}}{(1-\varphi)^{2.5}}
$$

- The effective density of the nanofluids:

$$
\rho_{n f}=(1-\varphi) \rho_{f}+\varphi \rho_{s}
$$

- The heat capacity of the nanofluids is given as follows:

$$
\left(\rho c_{p}\right)_{n f}=\varphi\left(\rho c_{p}\right)_{s}+(1-\varphi)\left(\rho c_{p}\right)_{f}
$$

- The thermal conductivity of the actual nanofluids is determined by the model Maxwel-Garnetts:

$$
\frac{k_{n f}}{k_{f}}=\frac{k_{s}+(n-1) k_{f}-(n-1)\left(k_{f}-k_{s}\right) \varphi}{k_{s}+(n-1) k_{f}-\left(k_{f}-k_{s}\right) \varphi}
$$

- The dimensionless parameters are:

$$
X=\frac{x}{H} ; Y=\frac{y}{H} ; \Omega=\frac{\omega H^{2}}{\alpha_{f}} ; \Psi=\frac{\psi}{\alpha_{f}} ; V=\frac{v H}{\alpha_{f}} ; U=\frac{u H}{\alpha_{f}} ; \theta=\frac{T-T_{h}}{T_{c}-T_{h}}
$$

- The equations can be written in the form dimensionless below

$$
\begin{aligned}
& \frac{\partial(U \Omega)}{\partial X}+\frac{\partial(V \Omega)}{\partial Y} \\
& =G r \cdot \operatorname{Pr}^{2} \cdot A \cdot\left[\cos (\phi) \frac{\partial \theta}{\partial X}-\sin (\phi) \frac{\partial \theta}{\partial Y}\right]+B \cdot \operatorname{Pr} \cdot\left[\frac{\partial^{2} \Omega}{\partial X^{2}}+\frac{\partial^{2} \Omega}{\partial Y^{2}}\right]
\end{aligned}
$$

where: $A=\frac{1}{\frac{(1-\varphi)}{\varphi} \cdot \frac{\rho_{f}}{\rho_{s}}+1} \frac{\beta_{s}}{\beta_{f}}+\frac{1}{\frac{\varphi}{(1-\varphi)} \cdot \frac{\rho_{s}}{\rho_{f}}+1} ; B=\frac{1}{(1-\varphi)^{2.5}\left[(1-\varphi)+\varphi \frac{\rho_{s}}{\rho_{f}}\right]}$

$$
\begin{gathered}
U=\frac{\partial \psi}{\partial Y} ; V=\frac{\partial \psi}{\partial X} \\
\frac{\partial}{\partial X}\left(\theta \cdot \frac{\partial \psi}{\partial Y}\right)-\frac{\partial}{\partial Y}\left(\theta \cdot \frac{\partial \psi}{\partial X}\right)=\frac{\alpha_{n f}}{\alpha_{f}}\left(\frac{\partial^{2} \theta}{\partial X^{2}}+\frac{\partial^{2} \theta}{\partial Y^{2}}\right) \\
\frac{\partial^{2} \psi}{\partial X^{2}}+\frac{\partial^{2} \psi}{\partial Y^{2}}=-\Omega
\end{gathered}
$$

The Rayleigh number, Prandtl and Grashof are given respectively:

$$
\operatorname{Pr}=\frac{v_{f}}{\alpha_{f}} ; R a=\frac{g \beta H^{3}\left(T_{h}-T_{c}\right)}{v_{f} \alpha} ; G r=\frac{g \beta H^{3}\left(T_{h}-T_{c}\right)}{v_{f}^{2}}
$$


The boundary conditions no dimensional are written as:

$$
\left.\begin{array}{l}
\text { On the left wall : } X=0 ; \Psi=0 ; \Omega=-\frac{\partial^{2} \Psi}{\partial X^{2}} ; \theta=1 \\
\text { On the Right wall : } X=1 ; \Psi=0 ; \Omega=-\frac{\partial^{2} \Psi}{\partial X^{2}} ; \theta=0 \\
\text { On the walls top and bottom : } \Psi=0 ; \Omega=-\frac{\partial^{2} \Psi}{\partial Y^{2}} ; \frac{\partial \theta}{\partial Y}=0
\end{array}\right\}
$$

The Nusselt number can be expressed as:

$$
N u=\frac{h H}{k_{f}}
$$

The coefficient of heat transfer is given by the Equation (17):

$$
h=\frac{q_{w}}{T_{h}-T_{c}}
$$

The thermal conductivity is expressed as:

$$
k_{n f}=\frac{q_{w}}{\frac{\partial T}{\partial x}}
$$

Substituting Equations ((17), (18)) and Equation (9) in Equation (16), and using the settings dimensionless, the Nusselt number is given by the equation below:

$$
N u=-\left(\frac{k_{n f}}{k_{f}}\right) \cdot \frac{\partial \theta}{\partial X}
$$

The average Nusselt number is:

$$
\overline{N u}=\int_{0}^{1} N u(Y) \cdot \mathrm{d} Y
$$

\section{Numerical Method}

The procedure of discretization of the equations (Guidelines Equations (11), (13), (14)) and the boundary conditions described by the Equation (15) have solved numerically using a finite difference technique. The equations of vorticity and energy are resolved using the method ADI (alternating direction implicit) and the equation of the function of current is resolved by the method SOR (successively over relaxation) while the difference in the near is used for the convective terms. The application line by line of the TDMA method (Tri-Diagonal Matrix Algorithm) (21) is applied to the equations of vorticity and energy until the sum of the residues becomes lower than $10^{-6}$. The developed algorithm has been implemented in the Fortran program.

The convergence criterion is defined by the following expression:

$$
\varepsilon=\frac{\sum_{j=1}^{j=M} \sum_{i=1}^{i=N}\left|\Phi^{n+1}-\Phi^{n}\right|}{\sum_{j=1}^{j=M} \sum_{i=1}^{i=N}\left|\Phi^{n+1}\right|}<10^{-6}
$$

where $\mathcal{E}$ is the tolerance; $M$ and $N$ are the number of grid points in the $x$ and $y$ 
directions respectively.

\section{Grid Testing and Code Validation}

The test of the mesh size is carried out in the case of $\operatorname{Ra}=10^{5}, \operatorname{Pr}=6.2, \varphi=10 \%$, $\Phi=0^{\circ}$ and $R=1$. The temperature and vertical speed calculated at half height of the cavity are presented in Figure 2 and Figure 3 for the sizes of mesh size $61 \times$ $61,81 \times 81,162 \times 162$ and $324 \times 324$. We can see that the differences in the calculated temperature and the speed are very low between the four meshes used and the size of the mesh size $81 \times 81$ is sufficient for $R=1$. Consequently, a uniform mesh size of $324 \times 81,81 \times 162,81 \times 81$ and $324 \times 324$ is used respectively for $R=0.25,0.5,1$, and 4 .

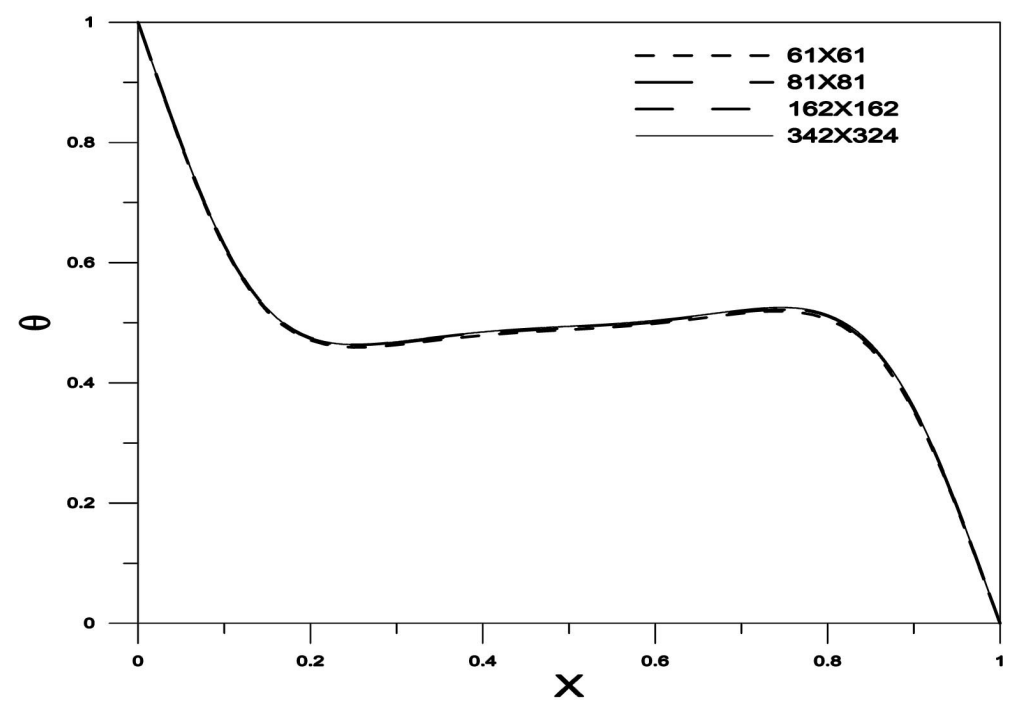

Figure 2. Temperature profiles at middle of hot wall cavity for various sizes of meshes $\left(\operatorname{Ra}=10^{5}, \operatorname{Pr}=6.2, \varphi=10 \%, \Phi=0^{\circ}\right.$ and $\left.R=1\right)$.

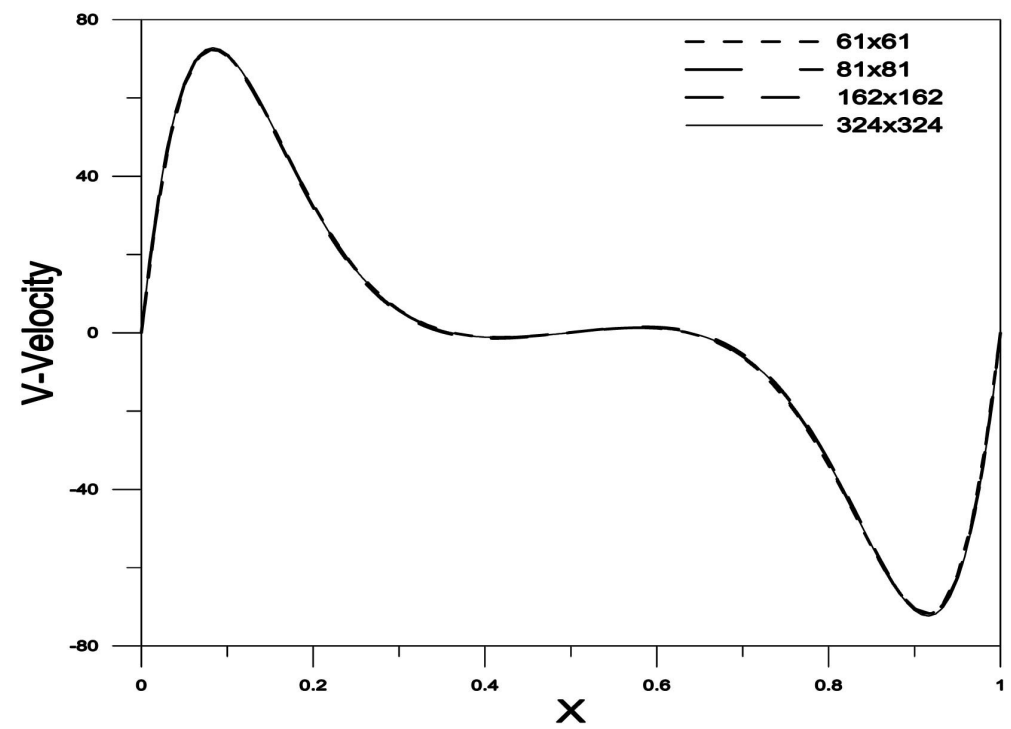

Figure 3. Velocity profiles at middle of hot wall for various mesh sizes $\left(\operatorname{Ra}=10^{5}, \operatorname{Pr}=6.2\right.$, $\varphi=10 \%, \Phi=0^{\circ}$ and $\left.R=1\right)$. 
In order to validate our code of calculation, we made a comparison with the previous results (Figure 4 and Figure 5), in the case of a square cavity without horizontal nanofluids. From this comparison, we see that there is a qualitative agreement between the results obtained by our code of calculation and those of previous work; this strengthens in the choice of our mathematical models and digital.

\section{Results and Discussion}

Once the code of calculation has been validated, we studied the influence of different

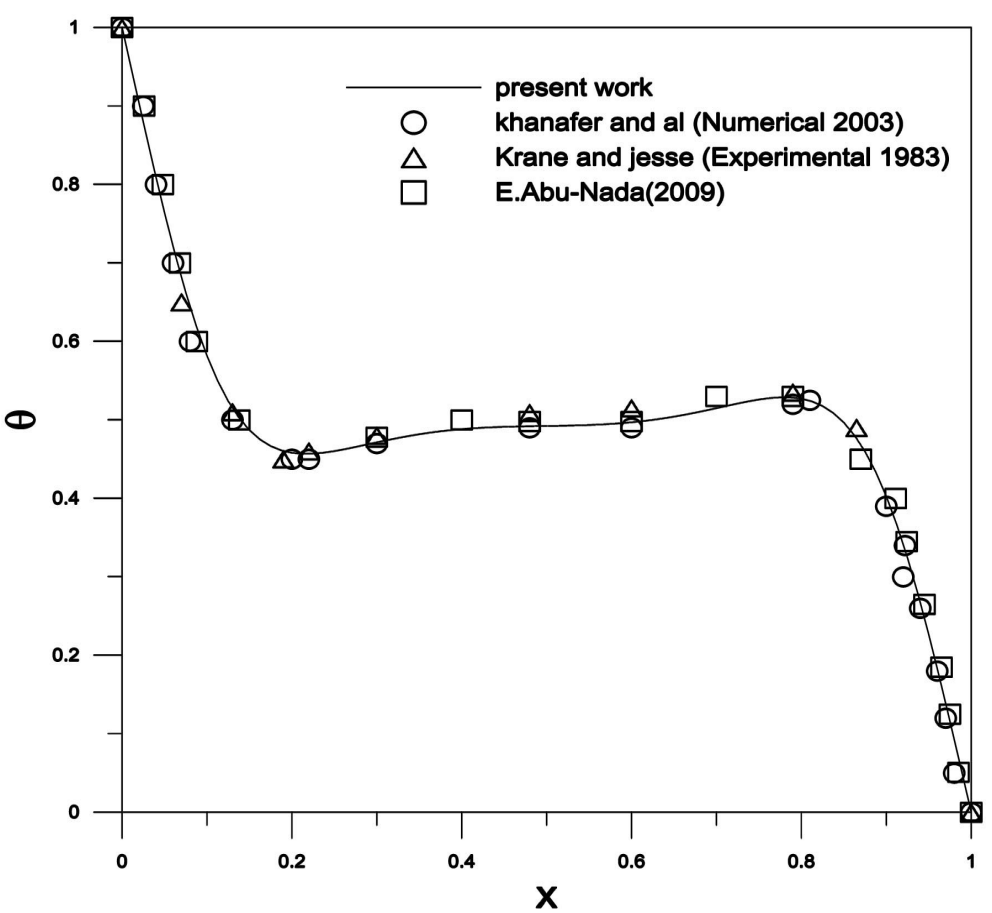

Figure 4. Comparison of the temperature distribution at mid-height of the cavity with previous work for $\left(\operatorname{Ra}=10^{5}, \operatorname{Pr}=0.7, \Phi=0^{\circ}\right)$.

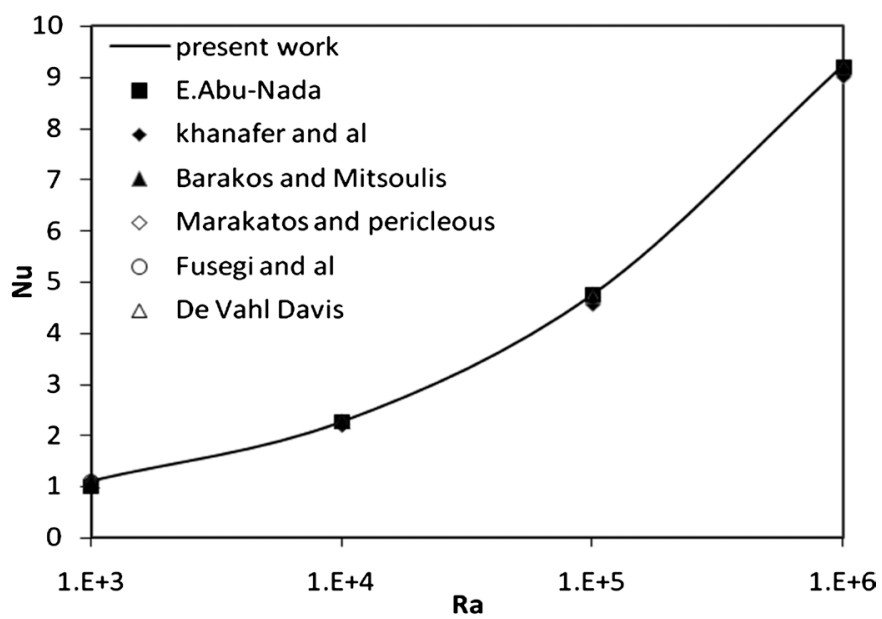

Figure 5. Variation of average Nusselt number Rayleigh numbers and comparison with other published works on the left wall $\left(R a=10^{5}, \operatorname{Pr}=0.7, \Phi=0^{\circ}, R=1\right)$. 
parameters on the thermal transfer. The results will be given in the form of the streamlines, and isotherms, average Nusselt as a function of correlation of the Rayleigh number between $10^{3} \leq R a \leq 10^{5}$, for different volume fractions of $0 \% \leq$ $\varphi \leq 10 \%$ and different angles of tilt angle $0^{\circ} \leq \phi \leq 90^{\circ}$. For the form factor $(R=$ $0.25,0.5,1$ and 4$)$, the results are presented as the streamlines and isotherms, the Nusselt number, temperature and velocity profiles.

For a horizontal cavity without nanofluid and $R=1$, being observed in Figure 6 a convective scheme for $R a=10^{4}$ and $R a=10^{5}$ but a conductive schema for $R a$ $=10^{3}$.

For a Rayleigh number $\left(R a=10^{4}\right)$, the isotherms become more deflected by report to the waves of $R a=10^{3}$, and the volume fractions higher always cause a slight deviation of the current lines and the isotherms between the nanofluid and the pure fluid. For a Rayleigh number $R a=10^{5}$, the isotherms become deflected by report to the curves of the two previous cases. The increase of the volume fractions entails a significant deviation of the isotherms and of the streamlines between the nanofluid and the pure fluid. The flow passes to a type of boundary layer (Figure 7).

Figure 8 shows the lines of current to the left and the isotherms to the right

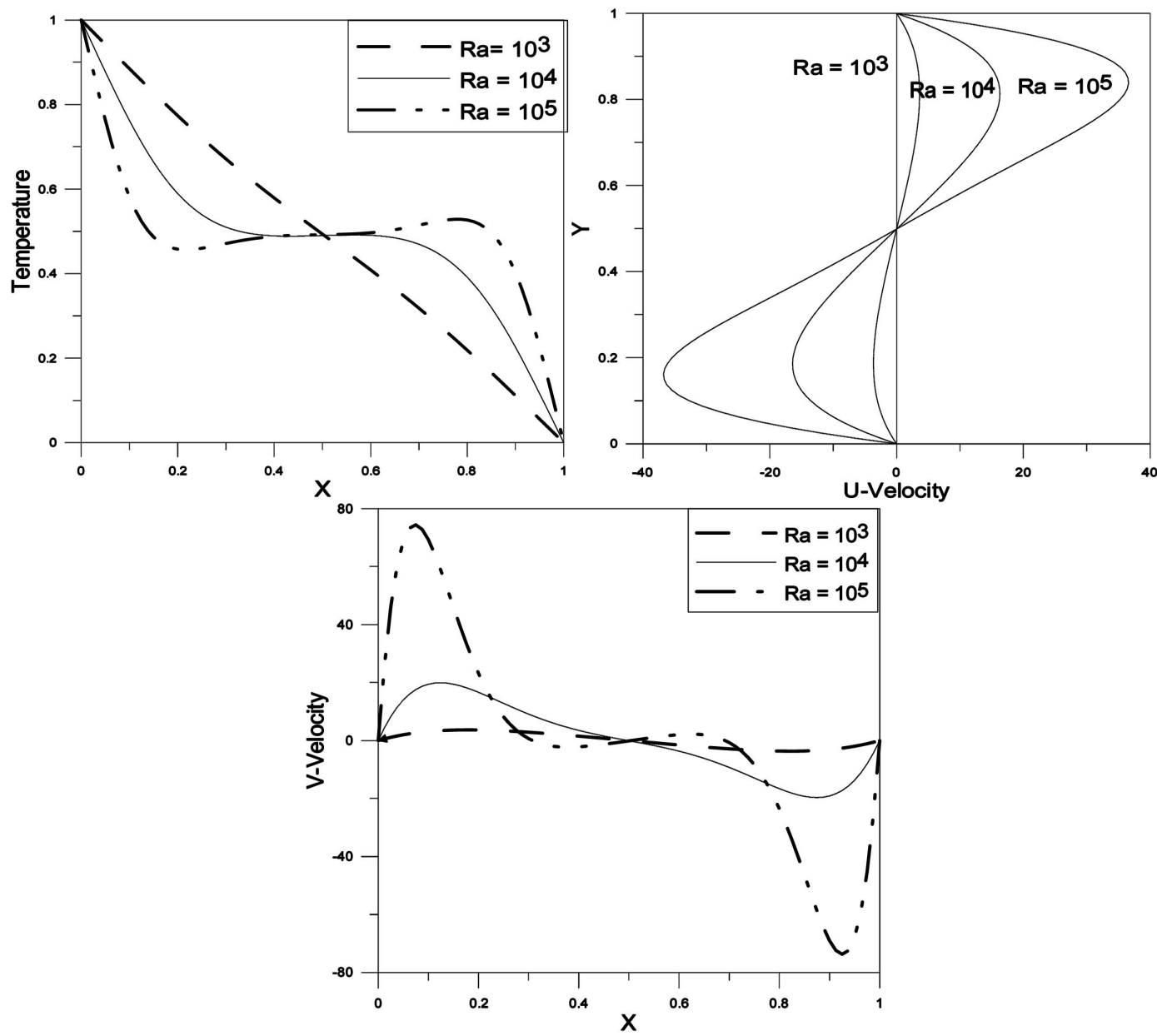

Figure 6. Temperature and velocity profiles in the middle hot of the cavity for $\operatorname{Pr}=6.2, \Phi=0^{\circ}, R=1$. 


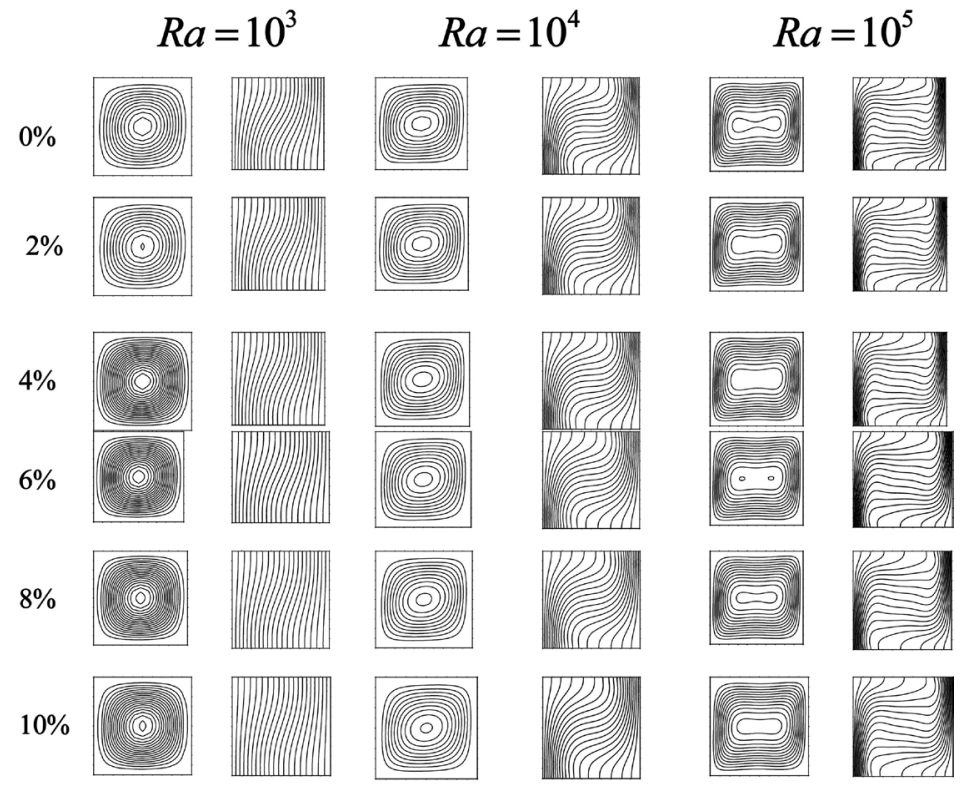

Figure 7. Streamlines (left) and isotherms (right) at various volume fractions for $(\operatorname{Pr}=6.2$; $\left.\Phi=0^{\circ}, R=1\right)$.

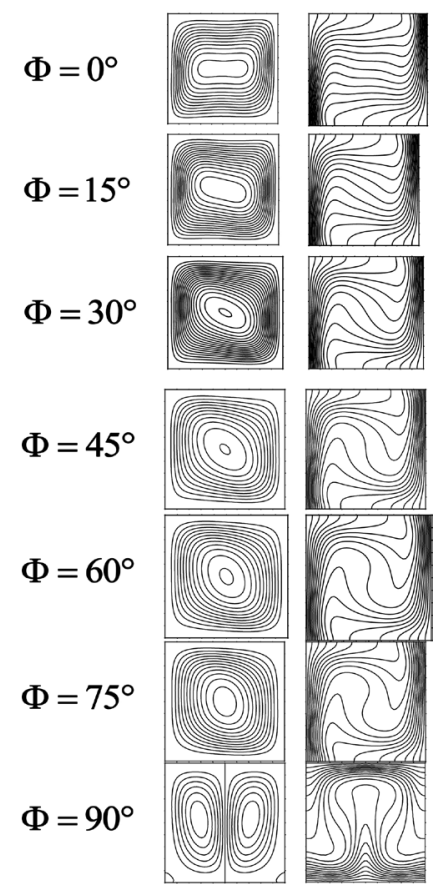

Figure 8. Streamlines (left) and isotherms (right) at different angles for $\left(R a=10^{5}, \operatorname{Pr}=\right.$ 6.2, $\varphi=10 \%, R=1)$.

for different angles of inclinations. It is observed that the shape of the main cell is sensitive to the inclination angle. For $\Phi=90^{\circ}$, the flow of Rayleigh-Bénard type is formed for the inner cavity because of the existence of the gravity in the enclosure. Figure shows that the transfer of heat is more pronounced for $\Phi=30^{\circ}$ and low for $\Phi=90^{\circ}$.

Figure 9 illustrates the isotherms and the streamlines at various angles of in- 
clinations $\left(\Phi=0^{\circ}, 15^{\circ}, 30^{\circ}, 45^{\circ}, 60^{\circ}, 75^{\circ}\right.$ and $\left.90^{\circ}\right)$ for $R a=10^{5}, \operatorname{Pr}=6.2, \varphi=10 \%$ and the form factor equal to 0.5 . It is observed that the shape of the main cell of the streamlines decreases with the increase of angle of tilt and deflected to the left. Small cells of recirculation in the lower right corner and in the upper left corner for $\Phi=90^{\circ}$. Figure 12(b) shows that the transfer of heat is higher for $\Phi$ $=15^{\circ}$ is low for $\Phi=90^{\circ}$.

Figure 10 shows the streamlines and the isotherms to different angles of inclinations $\left(\Phi=0^{\circ}, 15^{\circ}, 30^{\circ}, 45^{\circ}, 60^{\circ}, 75^{\circ}\right.$ and $\left.90^{\circ}\right)$ for $R a=10^{5}, \operatorname{Pr}=6.2, \varphi=10 \%$ and $R=0.25$.It is noticed that the shape of the cell is reduced with the increase of the inclination angle. It is observed a change in the cell structure of cells for $\Phi=$ $90^{\circ}$. That is why the transfer of heat is low, as shown in Figure 12 (c) to $\Phi=90^{\circ}$.

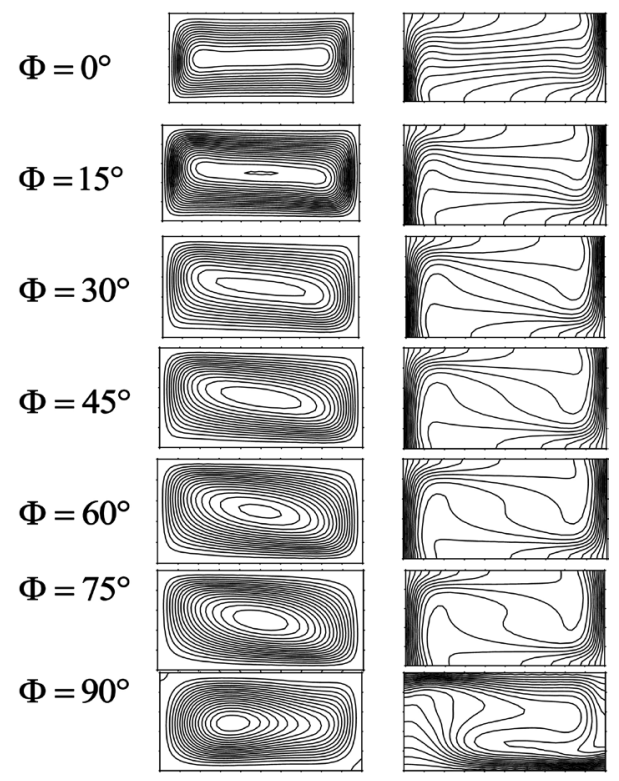

Figure 9. Streamlines contours (left) and isotherms (right) at various angles for $\left(R a=10^{5}\right.$, $\operatorname{Pr}=6.2, \varphi=10 \%, R=0.5)$.

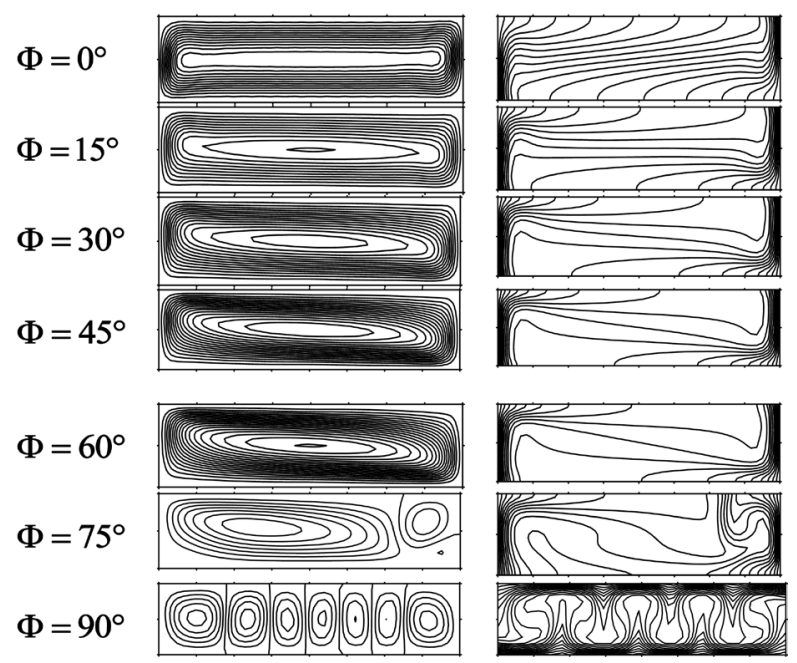

Figure 10. Streamlines contours (left) and isotherms (right) at various angles for $(R a=$ $\left.10^{5}, \operatorname{Pr}=6.2, \varphi=10 \%, R=0.25\right)$. 
Figure 11 shows the lines of the streamlines and the isotherms for different inclination angle $\left(\Phi=0^{\circ}, 15^{\circ}, 30^{\circ}, 45^{\circ}, 60^{\circ}, 75^{\circ}\right.$ and $\left.90^{\circ}\right)$ for $\operatorname{Ra}=10^{5}, \operatorname{Pr}=6.2, \varphi$ $=10 \%$ and the form factor equal to 4 . We see that the isotherms are insensitive to the inclination angle with the exception of the angle $\Phi=90^{\circ}$ to the cause of the decline in heat transfer, as shown in Figure 12(d).

\section{Conclusions}

In this work, it has been demonstrated the influence of the inclination angle

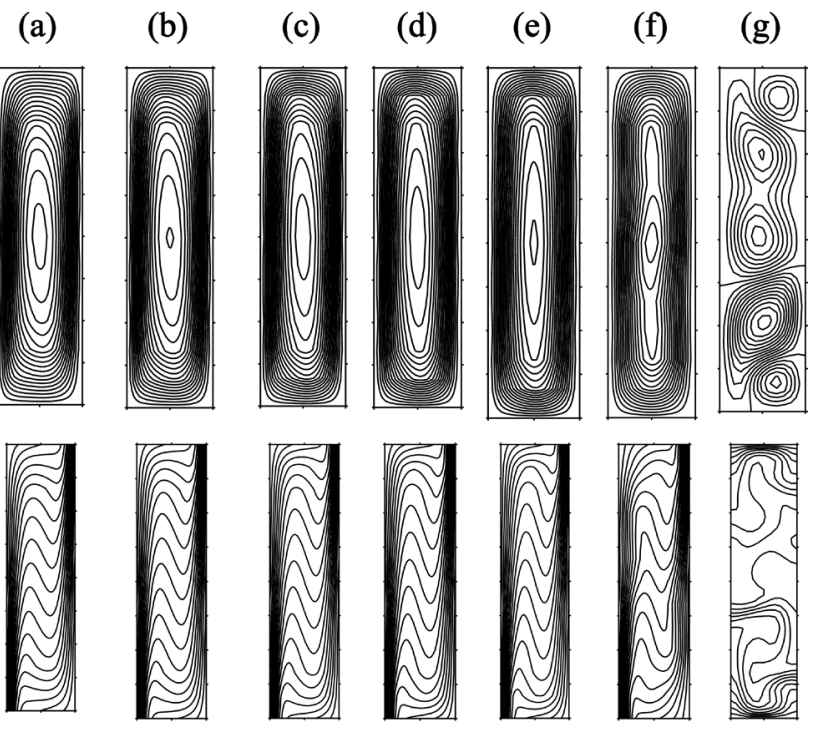

Figure 11. Streamlines (left) and isotherms (right) at various angles for $\left(R a=10^{5}, P r=\right.$ 6.2, $\varphi=10 \%, R=4)$ and $\Phi=0^{\circ}(\mathrm{a}) ; \Phi=15^{\circ}(\mathrm{b}) ; \Phi=30^{\circ}(\mathrm{c}) ; \Phi=45^{\circ}(\mathrm{d}) ; \Phi=60^{\circ}$ (e); $\Phi$ $=75^{\circ}(\mathrm{f}) ; \Phi=90^{\circ}(\mathrm{g})$.
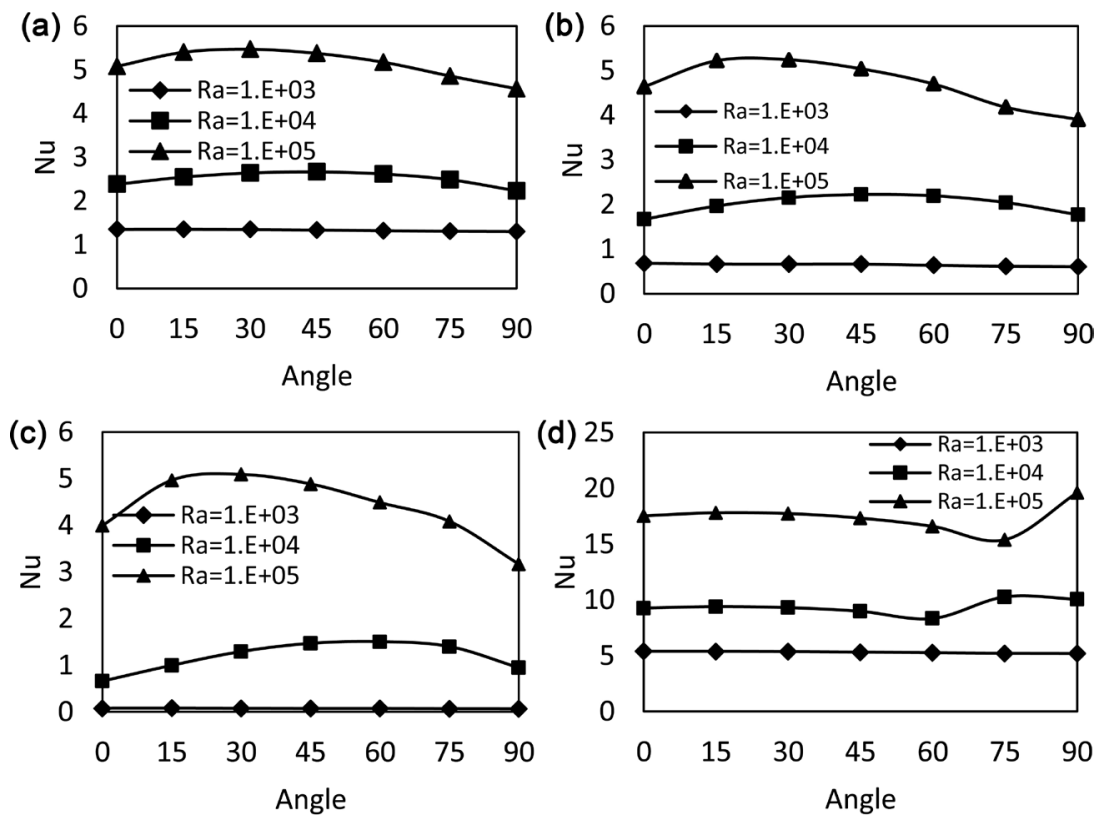

Figure 12. Variation of the average Nusselt number with different inclination angles for $\varphi=10 \%$ and the form factor $(\mathrm{a})=1,(\mathrm{~b})=0.5,(\mathrm{c})=0.25,(\mathrm{~d})=4$. 
as well as the volume fraction of nanoparticles and the form factor in cavity. The results have indicated that the addition of the nanoparticles of $\mathrm{Al}_{2} \mathrm{O}_{3}$ has produced a remarkable enhancement on heat transfer with respect to that of the pure fluid. The heat transfer increases with the increase of Rayleigh, but the effect of the concentration of nanoparticles on the the Nusselt number is more pronounced at low Rayleigh number than at high Rayleigh number. Inclination angle of the cavity is considered as a control parameter of the fluid flow and heat transfer. It has been seen that the heat transfer is more low to $\Phi=90^{\circ}$. But the increase of the values of the volume fraction becomes insignificant flow of fluid from this angle. Finally, the angle of tilt is a good parameter of control in the two cases of a cavity filled with pure fluid and nanofluid.

It was concluded that inclination angle where the heat transfer minimal has developed to a close relationship with the structure of the flow of transition. For the form factor of 1 and 0.5 , the secondary flow which occurs in the corners of the cavities was found to cause a decrease in the transfer of heat. For the form factor of 0.25 , a decrease of heat has occurred at the transformation of a unique cellular structure in a cell to seven cells. The transfer of heat is incremented for form factor equal to 4 .

\section{Conflicts of Interest}

The authors declare no conflicts of interest regarding the publication of this paper.

\section{References}

[1] Baïri, A., Laraqi, N. and García de María, J. (2007) Numerical and Experimental Study of Natural Convection in Tilted Parallelepipedic Cavities for Large Rayleigh Numbers. Experimental Thermal and Fluid Science, 31, 309-324.

[2] Oztop, H.F. and Abu-Nada, E. (2008) Numerical Study of Natural Convection in Partially Heated Rectangular Enclosure Filled with Nanofluids. International Journal of Heat and Fluid Flow, 29, 1326-1336. https://doi.org/10.1016/j.ijheatfluidflow.2008.04.009

[3] Tiwari, R.K. and Das, K. (2007) Heat Transfer Increase in a Two-Sided Lid-Driven Differentially Heated Square Cavity Utilizing Nanofluids. International Journal of Heat and Mass Transfer, 50, 2002-2018. https://doi.org/10.1016/j.ijheatmasstransfer.2006.09.034

[4] Choi, S. (1995) American Society of Mechanical Engineers. Developments and Applications of Non-Newtonian Flows EDF, 231, 99-105.

[5] Khanafer, K., Vafai, K. and Lightstone, M. (2003) Buoyancy-Driven Heat Transfer Enhancement in a Two-Dimensional Enclosure Utilizing Nanofluids. International Journal of Heat and Mass Transfer, 46, 3639-3653. https://doi.org/10.1016/S0017-9310(03)00156-X

[6] de Vahl Davis, G. (1960) Laminar Natural Convection in an Enclosed Rectangular Cavity. International Journal of Heat and Mass Transfer, 111, 1675-1693.

[7] de Vahl Davis, G. (1983) Natural Convection of Air in a Square Cavity: A Bench Mark Numerical Solution. International Journal for Numerical Methods in Fluids, 3, 249-264. https://doi.org/10.1002/fld.1650030305 
[8] Zaydan, M., Yadil, N., Boulahia, Z., Wakif, A. and Sehaqui, R. (2016) Compact Fourth-Order Formulation for the Resolution of Heat Transfer in Natural convection of Water-Cu Nanofluid in a Square Cavity with a Sinusoidal Thermal Boundary condition. World Journal of Nano Science and Engineering, 6, Article ID: 67550. https://doi.org/10.4236/wjnse.2016.62009

[9] Markatos, N.C. and Pericleous, K. (1984) Laminar and Turbulent Natural Convection in an Enclosed Cavity. International Journal of Heat and Mass Transfer, 27, 755-772. https://doi.org/10.1016/0017-9310(84)90145-5

[10] Jou, R.-Y. and Tzeng, S.-C. (2006) Numerical Research of Nature Convective Heat Transfer Enhancement Filled with Nanofluids in Rectangular Enclosures. International Communications in Heat and Mass Transfer, 33, 727-736.

https://doi.org/10.1016/j.icheatmasstransfer.2006.02.016

[11] Barakos, G., Mitsoulis, E. and Assimacopoulos, D. (1994) Natural Convection Flow in a Square Cavity Revisited: Laminar and Turbulent Models with Wall Functions. International Journal for Numerical Methods in Fluids, 18, 695-719. https://doi.org/10.1002/fld.1650180705

[12] Elsherbiny, S. (1996) Free Convection in Inclined Air Layers Heated from Above. International Journal of Heat and Mass Transfer, 39, 3925-3930. https://doi.org/10.1016/0017-9310(96)00047-6 


\section{Nomenclature}

$\begin{array}{ll}C_{p} & \text { Specific heat capacity }\left[\mathrm{J} \cdot \mathrm{kg}^{-1} \cdot \mathrm{K}^{-1}\right] \\ \boldsymbol{g} & \text { Gravitational acceleration }\left[\mathrm{m} \cdot \mathrm{s}^{-2}\right] \\ G r & \text { Grashof number } G r=\left(\beta_{f} H^{3} g\left(T_{h}-T_{c}\right)\right) /\left(v_{f}^{2}\right) \\ H & \text { Height of the cavity }[\mathrm{m}] \\ k & \text { Thermal conductivity }[\mathrm{W} / \mathrm{m} \cdot \mathrm{K}] \\ \overline{N u} & \text { Average Nusselt number } \\ N u & \text { Local Nusselt number } \\ p & \text { Pressure }[\mathrm{Pa}] \\ P & \text { The dimensionless pressure } \\ P r & \\ R & \text { Prandtl number } P r=\alpha / v_{f} \\ \text { Form factor } \\ R a & \text { Rayleigh number } R a=\left(\beta_{f} g H^{3}\left(T_{h}-T_{c}\right)\right) /\left(v_{f} \alpha\right) \\ T & \text { Temperature }[\mathrm{K}] \\ W & \text { Width of the cavity }[\mathrm{m}] \\ (X, y) & \text { Cartesian coordinates-dimensional }[\mathrm{m}] \\ (X, Y) & \text { Cartesian coordinates dimensionless } \\ u, V & \text { Velocity components in the directions } X, y\left[\mathrm{~m} \cdot \mathrm{s}^{-1}\right] \\ U, V & \text { Dimensionless velocity components }\end{array}$

\section{Greek symbols}

$\begin{array}{ll}\alpha & \text { Thermal diffusivity }\left[\mathrm{m}^{2} \cdot \mathrm{s}^{-1}\right) \\ \beta & \text { Thermal expansion coefficient }\left[\mathrm{K}^{-1}\right] \\ \varphi & \text { Solid volume fraction }[\%] \\ \mu & \text { Dynamic viscosity }\left[\mathrm{N} \cdot \mathrm{s} \cdot \mathrm{m}^{-2}\right] \\ v & \text { Kinematic viscosity }\left[\mathrm{m}^{2} \cdot \mathrm{s}^{-1}\right] \\ \rho & \text { Density }\left[\mathrm{kg} \cdot \mathrm{m}^{-3}\right] \\ \Omega & \text { Dimensionless vorticity } \\ \Phi & \text { Inclination angle }\left[{ }^{\circ}\right] \\ \Psi & \text { Dimensionless stream function } \\ \theta & \text { Dimensionless temperature } \\ \text { Indices } & \\ \mathrm{c} & \text { Cold } \\ \text { eff } & \text { Effective } \\ \text { h } & \text { Hot } \\ \text { s } & \text { Solid } \\ \text { f } & \text { Fluid } \\ \text { Operators } \\ \Delta & \text { Laplacian }\end{array}$

